Article

\title{
Decolonizing Pathways to Sustainability: Lessons Learned from Three Inuit Communities in NunatuKavut, Canada
}

\author{
Amy Hudson * and Kelly Vodden \\ Environmental Policy Institute, Grenfell Campus, Memorial University of Newfoundland, \\ Corner Brook, NL A2H 5G5, Canada; kvodden@grenfell.mun.ca \\ * Correspondence: ahudson@mun.ca
}

Received: 28 April 2020; Accepted: 25 May 2020; Published: 28 May 2020

check for updates

\begin{abstract}
Community led planning is necessary for Inuit to self-determine on their lands and to ensure the preservation of cultural landscapes and the sustainability of social-ecological systems that they are a part of. The sustainability efforts of three Inuit communities in Labrador during a Community Governance and Sustainability Initiative were guided by a decolonized and strength-based planning framework, including the values of Inuit in this study. This paper demonstrates that Inuit led planning efforts can strengthen community sustainability planning interests and potential. We situate the experiences of NunatuKavut Inuit within, and contribute to, the existing body of scholarly decolonization and sustainability literature. For many Indigenous people, including Inuit, decolonization is connected to inherent rights to self-determination. The findings suggest that decolonizing efforts must be understood and actualized within an Indigenous led research and sustainability planning paradigm that facilitates autonomous decision making and that is place based. Further, this study illustrates five predominant results regarding Inuit in planning for community sustainability that support sustainable self-determination. These include: inter and cross community sharing; identification of community strengths; strengthened community capacity; re-connection to community and culture; and the possibility for identification of sustainability goals to begin implementation through community led governance and planning processes.
\end{abstract}

Keywords: Inuit; sustainability; decolonization; self-determination; community planning

\section{Introduction}

Sustainability planning is necessary for community and cultural survival in remote Indigenous regions, like those in NunatuKavut (coastal Labrador). There is increasing recognition within the sustainability science literature of the need for place-based sustainability goals in Arctic communities that align with Arctic needs, based on the fact that these needs may in fact differ from global responses and efforts [1]. The literature reveals that both Indigenous and sustainability sciences contribute to the sustainability of "resilient landscapes", and to our understanding of them [2,3] (p. 1). This recognition further validates the need to work with Indigenous peoples in planning, by doing planning and sustainability scholarship differently. Sustainability science has been disconnected from Indigenous science and this has meant that Indigenous rights and knowledge have not been adequately engaged or privileged by Western scientific enquiry [3]. The participation of Indigenous peoples in planning processes have also been notably marginalized in Canada and around the world [4], with outside planning actors participating in the dispossession and marginalization of Indigenous peoples in the planning process [5]. This is despite the fact that "Indigenous peoples possess deep connections to place and knowledge of the land upon which they have lived for thousands of years" [6] (p. 428) 
and that planning is a vital aspect of governance, including Indigenous forms of governance that have also endured marginalization resulting from colonization [7]. Planners must be cognizant of this colonial history as "state-based planning has provided the conceptual and practical apparatus for institutionalizing marginalization" [8] (p. 643).

Sustainability work in rural and remote Indigenous communities offers important contributions to the sustainability science knowledge base. Recent collaborative, community-based research in the area of renewable energy in Labrador, for example, demonstrates that the voice of Inuit and their active participation in decision making is an integral part of process and outcome, building on the strengths and knowledge of Inuit themselves while reinforcing their role as decision makers and experts on their lands [9]. Land-use planning in the Nunatsiavut region of Labrador offers further insight into Indigenous planning in Labrador and the North. The land use plan of the Nunatsiavut government has been designed to "respond, first and foremost, to Inuit environmental, social, cultural, and economic interest" [10] (p. 438). Earlier research related to the process of mine development in Voisey's Bay, Labrador cited the apparent success of agreements reached between Indigenous and non-Indigenous parties that was based on "sustainability centered decision making" [11] (p. 343). Yet, O'Faircheallaigh [12] illustrates the tensions and complexities involved in the Voisey's development. The Province of Newfoundland (at the time), committed to advancing the development of the mine as expeditiously as possible, left the Innu and Inuit (the latter group represented by the LIA-Labrador Inuit Association) emphatic about their inclusion and participation in negotiations and reaching satisfactory agreements. The Innu were opposed to development early on but felt (along with the Inuit represented by LIA) that they had no choice but to seek inclusion as the development was set to proceed [12]. Moreover, Archibald and Crnkovich [13] point to a lack of Inuit women's representation and voice in the Voisey's Bay development, adding that analysis into the differential impacts on Inuit women were lacking in this development.

Indigenous planning has been broadly defined as a process whereby Indigenous people make their own decisions on their lands, and drawing upon the knowledge, values and principles within themselves to "define and progress their present and future social, cultural, environmental and economic aspirations" [8] (p. 642). To date, planning in practice has yielded limited opportunities to share and exercise principles and practices of Indigenous planning, particularly in the context of sovereign nations [7]. Indigenous planning has been identified as an approach that respects Indigenous sovereignty and worldviews [14], requiring sustainability planning approaches in Indigenous communities that are cognizant of inherent and sovereign rights to land and culture.

Indigenous peoples assert jurisdiction over their lands and within their communities in various ways (e.g., land claims, advocacy, agreements with the state, planning efforts). Most Inuit groups in Canada have settled land claims agreements with the state [15]. Inuit in NunatuKavut have not yet settled a final land claim agreement. However, they have a long history of asserting their rights on their land. Most recently, Canada has accepted the NunatuKavut Community Council (NCC), a governing organization that represents the Indigenous rights of NunatuKavut Inuit, into a Recognition of Indigenous Rights and Self-Determination (RIRSD) process to negotiate on matters of mutual interest between NunatuKavut Inuit and Canada [15]. Today, NunatuKavut Inuit continue to assert their rights on their land to ensure the future of their people and communities. Community-led sustainability planning during a Community Governance and Sustainability Initiative (CGSI) in NunatuKavut should be understood within a rights-based paradigm.

The CGSI (described in more detail below), was piloted in three select Inuit communities in NunatuKavut during 2017 and 2018 to facilitate opportunities for those communities to think about the future from the perspective of sustainability, grounded in their rights as Inuit belonging to their ancestral lands, and to plan accordingly. Baxter and Purcell [16] define Integrated Community Sustainability Planning (ICSP) as "a high-level overarching document for a community that is informed by sustainability principles and guides the community into the future" (p. 35). ICSPs are one example of a model of sustainability planning that have been employed across Canada, including the 
province of Newfoundland and Labrador (NL) [17]. This paper presents an alternative Indigenous sustainability planning perspective and approach, particularly one that is grounded in the efforts of Inuit in NunatuKavut through a community led, decolonized and strength-based planning framework. This study builds upon normative ideas of community sustainability planning, like ICSP, at the same time as privileging Inuit knowledge, expertise and values that are vital to the planning process within Inuit territories.

Throughout this paper, we draw upon and situate Inuit planning within the overarching concept of decolonization, while building on the work of Indigenous scholars who have informed our analysis such as Jeff Corntassel [18], Pam Palmater [19], Linda Smith [20], and Shawn Wilson [21]. In NunatuKavut, where Inuit are planning for sustainable communities and futures, planning efforts invoke a necessary and simultaneous process of self-decolonization. The decolonizing of the self is integral to a larger order of decolonization and to anti-colonial sustainability efforts that connect both theory and practice. The concept of "sustainable self-determination," a term coined by Indigenous scholar Jeff Corntassel [18], is useful for understanding Inuit planning in NunatuKavut as a pathway to decolonized self-determination. In the context of NunatuKavut Inuit, we argue that Inuit led, decolonized and strength-based planning, can strengthen community sustainability planning interest and overall potential. The results of this process give rise to sustainable self-determination that contribute to the preservation of cultural landscapes and the sustainability of social-ecological systems that make up Inuit society.

\subsection{Decolonization and Sustainable Self-Determination}

Community sustainability planning approaches designed and developed by and for Indigenous peoples are integral to Indigenous self-determination efforts. Indigenous governance practices and methods, including planning efforts, can be conducive to the creation of societies that are more sustainable [22]. Recent research with First Nations in Saskatchewan, for example, point to the success of Indigenous planning when the approach results in trust relationships between the First Nation community, other participants and university researchers and community capacity is strengthened [23]. The ability of communities to self-determine in ways that reflect Indigenous ways of knowing and being is in part, contingent upon Indigenous autonomy and control of decision making about the future. Yet, Indigenous community planning and approaches to planning have often been marginalized by external decision makers [4]. Externally controlled community development and planning processes are indicative of colonial ideas and mentalities that undermine Indigenous knowledge and expertise in favor of Western European knowledge in deciding matters for the future of Inuit and their lands. Therefore, any approach to decolonized community planning must be cognizant of historic and modern impacts of colonization.

Indigenous scholar, lawyer and advocate Pamela Palmater defines colonization as a process by which "a state or colony attempts to dispossess and subjugate the original Indigenous peoples of the land," [19] (p. 3) and she maintains that colonization, in this form, has not ended for Indigenous peoples. Corntassel [24] portrays colonization as a dysfunctional force that disconnects peoples from their home, land and culture. He maintains that Indigenous resurgence is about connecting to home, land and culture, a central feature of decolonization.

Decolonization has been defined and drawn upon by academia, institutions and governments. Leading Indigenous scholars like Linda Smith [20] and Margaret Kovach [25] have engaged decolonization discourse, enlightening a world that resonates for many Indigenous peoples and offering insights into how to think about and do research differently. Conceptually and practically, decolonization is a necessary and integral step towards acknowledging and confronting the legacy of colonization (past and ongoing). Decolonizing work is an ever evolving, dynamic and site-specific process. Decolonization and decolonized planning can be further linked to Corntassel's key concept of sustainable self-determination, with a view towards privileging and bringing attention to Inuit efforts to self-determine that may otherwise go unnoticed by outside decision makers or planners. 
We engage decolonization as a process that sets the foundation for everyday acts of resurgence, including Indigenous-led planning. Corntassel [24] recalled pathways to decolonization that are and can be realized through Indigenous led self-determination efforts. Learning from Fanon [26], we are alert to the reality that decolonization implies a commitment to embracing differing worldviews and perspectives, and the tensions that are inherent in this process. This entails moving beyond European norms and ways of thinking. Decolonization must be a unique and context specific process that includes individual and collective acts of resurgence, revitalization and determination contingent upon time and place, in Indigenous peoples' pursuit of self-determination. We argue that a decolonial approach to community sustainability planning in NunatuKavut is integral to ensuring that the sustainability goals identified and the planning process itself is embedded in a vision for the future that is self-determined by Inuit in their time and place and reflective of Inuit values and ways of knowing and being. In this way planning can, in turn, further sustainable self-determination and create the pathways to decolonization observed and called for by Corntassel and others.

\subsection{Grounding Decolonization: Recognizing the Role of Indigenous Peoples and Their Communities}

The participation of planning actors in the "dispossession, oppression and marginalization of Indigenous peoples has implications for the field" [5] (p. 403). Recognizing colonial realities allows for the challenging of western, well intentioned, and persistent assumptions imbued in planning that seek to "better the world" [5] (p. 403). Indigenous claims to self-determination, land restitution, etc., make the need to challenge planning assumptions evident and timely. When Indigenous people question ongoing normative assumptions and practices by privileging their own ways of knowing and being, opportunities arise to plan for a future that is shaped by their own worldview(s). The ability to inform planning approaches from one's own space (values, goals, etc.), as opposed to outside perceptions of what is good or necessary, is optimal for decolonizing planning processes that are Indigenous designed and led.

In many cases, Indigenous peoples, communities, nations and governments continue to work towards building a future and a path that is reflective of their values, perspectives and worldviews, despite ongoing colonial interference. Indigenous peoples have been finding opportunities to revitalize as nations, while making small movements towards reclamation-whether that be of culture, language, education, political society, etc. $[20,24]$. We contend that acts of resistance and resurgence in these forms are a necessary part of the process of decolonization and are necessarily linked to community planning, yet they often go unrecognized as a source of knowledge or expertise integral to planning work by outsiders. Additionally, these acts are rarely upheld or highlighted as integral and tangible decolonizing work, particularly by states and/or institutions who often set the standard for how reconciliation and/or decolonization is to be approached in Canada and within institutions (i.e., academia). This provides evidence that as a society we are still unwilling to really learn or accept the knowledge and expertise of Indigenous peoples in their place and as autonomous rights holders on their lands. Realities like these are well established and have been demonstrated over time as the courts have consistently failed to consider Indigenous people's perspectives in law and legal analysis $[27,28]$. This too has implications for the field of Indigenous sustainability planning.

The idea that the state and its government know best is an age-old way of thinking and doing and is perpetuated in relations with Indigenous peoples, and even in times of good will and positive intention. Eisenberg, Webber, and Coulthard [29] maintain that Indigenous peoples and communities themselves are the sole agents with the power to recognize and give expression to the knowledge that make up who they are. When Indigenous peoples, organizations, and communities take on the arduous tasks of reclamation through tangible and practical everyday acts on their lands and in their communities, they are in fact pursuing and leading decolonizing work that lends toward self-determination.

A strength-based approach to community sustainability planning, that rested on the values, hopes and goals of Inuit in this study, guided the approach of the CGSI. This work exists as an example of a community based and community driven approach to decolonization, grounded in 
and guided by connection to home, values and individual and collective determination to ensure the survival and preservation of community and culture. In what follows, we describe and interpret acts of resurgence, revitalization and sustainable self-determination in three Inuit communities within community sustainability planning efforts as part of, and emblematic of, a larger process of decolonization.

\section{Methodology}

This research was guided by Indigenous and qualitative research methodologies. Indigenous research methodology is integral to understanding and making space for sustainable self-determination in Indigenous communities. The ability to share, learn and listen through stories is fundamental to understanding Indigenous worldviews and perspectives and storytelling is an integral and valued method and approach [30]. This research seeks to ensure that the voice and knowledge of Inuit are privileged and drive the findings of this paper. A culturally relevant research paradigm (as employed in this research), ensures that Indigenous methods are validated and used [21], contributing to decolonization and supporting the assertion of rights and sovereignty. Research within this paradigm remains cognizant of a history of colonially rooted research practices (including a tradition that privileges research practices that are value neutral), while remaining committed to research that seeks to better the well-being of Indigenous peoples as per their ways of being and knowing [20]. Booth and Muir [31] understand Indigenous planning as an attempt to "recognize the unique and specific legal, political, historical, cultural and social circumstances in which the world's Indigenous peoples find themselves" (p. 422). It can be argued that this is also the case for the Inuit of NunatuKavut and their representative governing organization the NunatuKavut Community Council (NCC), as they seek to enhance capacity and knowledge for planning that is specific to their needs, interests, and historical and modern realities and as they engage in culturally relevant planning to advance self-determination efforts. This research initiated and facilitated community capacity strengthening efforts so that community members and leaders are better equipped to effectively engage in the planning of their communities for the future and validated in doing so.

\subsection{Community Governance and Sustainability Initiative (CGSI): A Framework for Designing and Implementing Community Led and Responsive Research and Planning Practices}

There is a growing interest in planning that is adaptable to uncertain conditions and realities [32]. Adaptability is a central feature of Inuit societies. Cognizant of the social and political history of the Inuit communities in NunatuKavut, and moreover, a legacy of research on and within Indigenous communities broadly, the overall approach to this research was to work with NunatuKavut Inuit and to locate positive attributes of their communities, and to privilege Inuit worldviews and perspectives in the process. We collaboratively identified approaches and ways of doing based on what has worked well in the past, locating expertise and assets within communities themselves, all to further strengthen and benefit from the adaptive capacities required to vision and plan for a positive and vibrant future that is relevant to Inuit themselves.

We examined contributions in NunatuKavut in the areas of self-determination, decolonization, resurgence and rights that are Indigenous led and inspired, building upon scholarly literature in discussions surrounding decolonization and sustainability. The worlds of academia and Inuit community life have come together in this project to support the creation of space and opportunities for community sustainability planning. These opportunities have implications for the preservation of culture and communities in NunatuKavut, and for the methodology used in this research.

Respectful community engagement was guided by the work of leading Indigenous scholars in the field like Smith, Wilson and Kovach, along with Hudson's connection to her home community and to NunatuKavut generally. This approach to community engagement helped to ensure that the research study was informed by the community in both purpose and methods. We also drew from the expertise, knowledge and guidance of three NunatuKavut communities: Black Tickle, Norman Bay 
and St. Lewis (Appendix A, Table A1). This research was community led and driven and the research methods support this end. Hart [33] writes of research that is "structured within an epistemology that includes a subjectively based process for knowledge development and a reliance on Elders and individuals who have or are developing this insight" (p. 9). Hudson's own experiences, as a result of growing up in and belonging to one of the pilot communities of this study and her work with the NCC, further embedded and ensured accountability to this research approach.

Strength-based decision making and planning was introduced as the framework for our discussions. This assisted in situating Inuit participants as knowledge holders and experts on matters that impact them and on their lands. This strength-based approach is particularly fundamental to decolonized sustainability planning in NunatuKavut. Deficit based research has often been conducted in Indigenous communities, failing to acknowledge and respect Indigenous knowledge and expertise [34]. The use of strength-based planning allowed for Inuit worldviews, values and perspectives to lead and guide the planning process. Planning with and by Indigenous peoples in this way has elsewhere resulted in positive outcomes across a range of areas like culture, identity-building, healing, etc. [35]. In this study, dialogue around strength-based thinking was integral to envisioning a sustainable future. It is noteworthy that females pre-dominantly led the sustainability work and all three community sustainability coordinators (described below) were female. In remote communities such as these, there is often a tendency to focus on what has not been working in communities, or how governments or other governing bodies are not working, without looking at the potential and individual and collective agency that already exists within communities. Strength based discussions, asset mapping and visioning exercises assisted communities in maneuvering around this paradigm to get to a place of planning without the baggage of what has gone wrong in the past, which stands in the way of planning a desired future. Planning from a place of strength that privileges local Inuit knowledge is also key to the pursuit of sustainable self-determination.

As a way to initiate the CGSI a regional workshop was held in Happy Valley-Goose Bay (HVGB), Spring 2017. This gathering brought together the three pilot communities, including three representatives from each of the communities. We worked with community participants and engaged in various awareness, skills and capacity building exercises. They included: (a) strength-based decision making and planning; (b) community visioning exercises; (c) community asset mapping; (d) community engagement; and (f) proposal writing.

Following the initial gathering in HVGB, pilot community participants applied and furthered the lessons that they had learned once they returned home to their community (e.g., asset mapping). As research lead, Hudson identified an external funding opportunity to further the community sustainability planning work. This allowed NCC to employ a community sustainability coordinator in each of the three communities for a period of seven months. Throughout the scope of this work, and working directly with Hudson, community sustainability coordinators were able to solidify sustainability committees in their respective communities and then co-led the committees in a range of activities and areas relevant and localized to each community. Hudson oversaw the work of the coordinators as NCC lead and as a part of this study. The coordinators furthered asset mapping exercises, participated in and co- led visioning exercises and activities (feast, cultural events, community games, etc.), wrote proposals, and engaged in networking opportunities with stakeholders.

\subsection{Recruitment and Data Collection}

Interactive workshops, gatherings and community meetings supported both collaboration and consensus building discussions and provided the space and environment to engage participants throughout 2017 and into 2018. These workshops, meetings and gatherings were predominantly held in the study communities, with the exception of two larger gatherings that brought together all three communities to learn and share in a larger setting in HVGB. Recruitment strategies within communities relied on local knowledge and expertise from community members and the NCC. Other NCC partners, past and present, with experience and knowledge of NCC governance and land claims, were also 
invited to participate. Participants were contacted in various ways depending on the data collection strategy (i.e., email, public notices, in person, email). In order to achieve the goals of the project across three communities, it was necessary to employ a multi-dimensional approach to community outreach and engagement, and the project lent itself to learning and refining best practices, in working with the three communities.

Qualitative data collection methods included one on one interviews, focus groups, and surveys. Participants were recruited by email, telephone and word of mouth for each of these methods. Four one on one interviews were conducted in the communities (one from Black Tickle, two from St. Lewis, one from Norman Bay). Additionally, two external interviews were conducted with individuals who have been participatory to NCC's land claim and research journey over the past two decades. See Table A2 for a detailed list of activities undertaken with participants from each of the three pilot communities. Interviews occurred simultaneously with other forms of data collection. We chose interviews as a data collection method given the centrality of interviewing to qualitative methodology. However, it was clear that action-oriented data collection that directly engaged participants in gatherings (like those described above) and settings designed to share and learn from one another, were much more conducive to collecting rich data and in engaging participants throughout the research. In some instances, such as the two gatherings in HVGB, stakeholders were invited by email to participate, listen and respond to community interests and goals. Some of the stakeholders in attendance included representatives from funding agencies (e.g., Atlantic Canada Opportunities Agency), business advisors from Nunacor (NCC's business arm), and academics in related fields at Memorial University.

The two larger, centralized gatherings, also referred to as workshops, were held in HVGB and brought representatives from all three study communities together. Recruitment for these two gatherings was done by contacting the local governing structure by telephone and email in each of the study communities (municipality, local service district, recreation committee). It was appropriate to work with the local governing boards to not only seek their interest in the project, but to identify recruits to attend the gatherings in HVGB. The second gathering, recruited in much the same manner, also hosted a focus group discussion with participants from all three communities. The dynamics of these gatherings were comfortable, supportive, open and transparent. Existing best practices in engagement by NCC in the past also assisted in implementing spaces that were conducive to sharing and dialogue. Community gatherings ranged in size and were influenced by community population size, with 25+ people attending in Black Tickle at a full day youth and community event, approximately six people in Norman Bay and 40+ people in St Lewis at a community feast and youth/family event. The community feast in St. Lewis resulted in 43 written submissions by community members detailing what they value most about life in St. Lewis.

There were four focus groups in total (one in each individual pilot community and one collective focus group at the second sustainability gathering in HVGB-described above). There were seven participants in the focus group in Black Tickle, two in Norman Bay, six in St. Lewis and ten in the HVGB workshop. Participants attended and engaged in two workshops in Happy Valley Goose Bay with ten participants in each workshop. Survey respondents totaled 26 in Norman Bay and St. Lewis. The surveys sought to elicit information about the age, gender, and connection community members felt towards their home. The surveys were not initiated or completed in Black Tickle as the community is all of Hudson's relations. While surveys assist in gathering relevant information for analysis, in this context the use of a survey in Hudson's home community felt too impersonal. Hudson knows each individual personally and shares ancestral ties and modern-day kinship and social networks with them.

Further data were collected through collaborative community development efforts (planning and ideas sharing), and a manual to guide community planners/coordinators was compiled by the sustainability coordinators in this study. The development of this manual was informed by work in each of the pilot communities through a process of reflection and community engagement. In addition, written submissions from individual community members about what they value most about their community were collected and compiled separately into community booklets. There were 12, 12 and 
26 individual submissions respectively, numbering 50 submissions in total. Participants were recruited by advertisement, telephone and word of mouth.

\subsection{Data Analysis}

One on one interviews and focus groups were audio recorded and transcribed. Notes were taken and reflected upon in instances where audio recording did not take place. Prominent themes from all sources of data were identified and interpreted. Due to the Indigenous storytelling nature of data collection, the interpretation of data sets was validated during conversations, focus groups, and gatherings with participants. This ensured that participants had ample opportunity to reflect, discuss, share what they meant, and what they saw as important for the future. The community led and driven approach of this research meant that participant stories (i.e., submissions on what they love about community, asset mapping, visioning), reflect the voices of communities in this study and explicitly reinforce connection to community. Thus, community voice and direction underscore the results and discussion that follows and will be central to any future efforts that result from planning for sustainability in NunatuKavut.

\section{Results: Planning for Sustainability in NunatuKavut}

Five predominant results regarding Inuit planning, through the Community Governance and Sustainability Initiative (CGSI), materialized from this study, identified in Table 1 below. A discussion of each of these key results follows. These results illustrate how Inuit led community planning materialized in this study. These results offer an alternative approach to conducting Inuit community led sustainability planning that is guided by a decolonized and strength-based framework. In doing so, we respond to the above described call by Johnson et al. [3], Ugarte [5], McGregor [6] and others to engage and privilege Indigenous rights and knowledge and participation by Indigenous peoples in planning processes.

Table 1. Key Results.

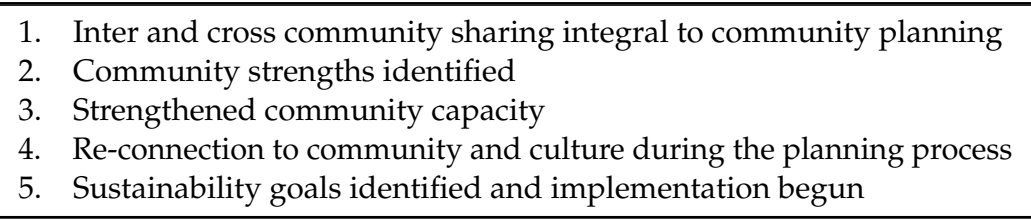

The results reflect the multifaceted engagement of participants, and their contributions to this study, and are embedded and interpreted from a place of strength, autonomy and Inuit rights. In sum, the results point to a reality whereby commitment and connection to community is paramount and where knowledge and expertise has been borne from generations of living on and with the land and this knowledge is paramount to continued community planning and ultimately survival.

\subsection{Inter and Cross Community Sharing Integral to Community Planning}

Storytelling and knowledge passed down through generations are integral to the continuity and survival of Inuit societies, and in community sustainability planning efforts. The exchange of knowledge and expertise between Inuit and as it relates to their collective and individual experiences living on and with the land, within their respective communities and in the region as a whole, is an integral method within a decolonized and strength based planning framework. This is particularly relevant given the many accounts of how Indigenous peoples have been marginalized by external planners in planning processes on Indigenous lands [4]. Therefore, this approach seeks to privilege the voice of Inuit in planning a future on their own terms, and from their own perspectives. This also assists in motivating and empowering community members to reject a history of outsider knows best, inherent in mainstream Western sustainability planning, and to reclaim agency on their lands. Previous in depth 
research with NunatuKavut Inuit demonstrates the important role of storytelling and local knowledge and expertise to family and community survival [33]. Participant feedback about participation in the sustainability workshops revealed that participants saw value in coming together, across communities, to share and learn from one another. Community members gained encouragement to move forward in their own communities as a result of this co-learning and sharing. Community participants thought deeply about the values, assets, and overall strengths of their respective communities and how their communities were similar and dissimilar in NunatuKavut, as well as how they could support one another and learn from one another moving forward. One of the participants commented:

\begin{abstract}
"During these workshops I've learned with my community how to try and embrace the negative in our community and turn it into a positive. I've experienced other communities address issues that are similar to ours that I didn't know existed... Just overall this experience have been amazing and so insightful".
\end{abstract}

Demonstrating further the importance of relationship building to this work, another community participant described the key benefits she gained from participating in the process. She stated: "The connections and relationships/bonds I made. The confidence to return to my community with knowledge I didn't know before".

Sharing and co-learning was key to the success of this work. While communities often work alone to achieve their goals (lack of resources and time to collaborate and remote geography, contribute to this reality), the CGSI allowed for opportunities for cross community knowledge sharing and engagement to take place in non-competitive and open spaces that also sought to strengthen community skills. This helped to reduce participant feelings of isolation and alienation in visioning and community planning.

\title{
3.2. Identification of Community Strengths
}

In an effort to build on the positive momentum gained from inter and cross community knowledge sharing and strength based dialogue, facilitated discussions around community strengths created and directed opportunities for community members in each of the pilot communities to submit (in writing or in picture form) their own thoughts and ideas about what it is that they value about their community. This method acknowledged and validated the strengths inherent in community connection. As Inuit continue to evolve and adapt to a changing world that impacts their environment, they are well positioned to identify the strengths that are integral to the continuation of their societies. NunatuKavut Inuit are deeply connected to the lands, waters, ice and kinship ties that make up their society and communities. Yet, they are often excluded from aspects of planning and decision-making on their lands. The identification of strengths by Inuit themselves has ensured that all sectors of society that are regarded as significant, have been included in the planning process and was an important part of ensuring a decolonized approach to community planning-one that acknowledges the various sources and sites of knowledge common to Inuit.

Submissions varied in length and individual participants described their connection to place and homeland. These submissions were compiled and integrated into three booklets. They are as follows: Why I love Black Tickle, Why I love Norman Bay, and Why I love St. Lewis. These stories were integral to deepening our understanding of community values in NunatuKavut. Below are two examples from the submissions that were compiled.

"The peacefulness. The beauty of the land. I love all what BT is. The way the bog smells in the spring when everything is starting to thaw, sitting out on the point and watching flock after flock of birds flying by. The smell of wetness in the air as you go in over the land berrypicking. The beautiful colours of bright green grass as you climb the hills in July, the sound of seagulls going crazy for a feed of fish when the fishermen come in with their catch. The way the lights dance on the water on a beautiful calm summers night. The way the town looks after its first snowfall. Seeing the kiddies going from 
pond to pond to check the depth of the ice for skating time and the memories come racing in of when you were a child and the amount of hours you spent on them same ponds growing up".

"Norman Bay gave my husband and I a quiet, peaceful, and safe place to raise our children. Everybody's children played together. If you knew where one child was, you knew where the whole bunch was. I can honestly say I was never bored. The isolation from other communities never bothered me and still don't. I have always felt safe here. People would always be there to give help when it was needed, no matter what and it's still that way today. We don't have far to go for our wild foods and berries or wood for our heat".

The success of this strength-based exercise demonstrated the deep and enduring connection that individuals have to their homeland. In addition, by eliciting positive and strength-based versions of home and community, we strengthened and situated our collective understanding about what is most important to community members as they prepare and plan for the future. Community members became re-focused around what is most important to them during this process as well. Simultaneously, community sustainability coordinators were building on asset mapping skills they had learned during the workshops in HVGB and they each worked in their respective communities to identify assets in diverse areas like culture, social, human, financial, to name a few. Asset mapping, focused on community strengths, and served to reinforce that knowledge and expertise already exists within the communities. Participants began to see themselves reflected in this way and this furthered their ability to think about what they could achieve in their respective communities. This method further ensured the active inclusion of Inuit in the planning process and that Inuit values were reflected in the planning process. For example, we learned from participants that maintaining traditional skills, local knowledge of the land, including the use of knowledge passed down through generations, are key strengths and important considerations in sustainability planning work.

\subsection{Strengthened Community Capacity}

Through decolonized community engagement that used a strength-based approach, participant awareness, skillsets and capacity were strengthened in areas of interest and relevance to community members in pursuit of community planning. This further enabled the active participation and engagement of community sustainability coordinators in leading sustainability planning in their hometowns. Capacity strengthening exercises were conducted with the sustainability coordinators in the following areas: (a) community engagement, (b) community strengths and, (c) sustainability goals and visioning. This method has had positive implications for community, and it ensured that capacity strengthening efforts directly benefited the communities themselves. These measures were taken to avoid the pitfalls common to Western scientific research whereby external researchers enter a community, conduct the research, and then leave with the knowledge (gained through dialogue with Indigenous participants), and then analyze and use this knowledge outside of the community itself. By ensuring that capacity strengthening efforts focused directly on furthering the leadership of community members, we sought to avoid such colonial research practices.

Conversations and capacity strengthening opportunities took place with community sustainability coordinators and other participants from the three pilot communities. We talked about why participants were engaged in community sustainability work, why it was important for them, and for other community members, to be a part of change for the future in their respective communities. These conversations allowed us to better understand collectively why people remain connected to their community, and the values surrounding this connection. Together, we were better able to think of relevant and meaningful ways to engage communities in important conversations about the future, and in community planning projects. In reflecting on one of the workshops a participant stated: "What a strong group of community leaders. I'm so impressed by the ideas and the hard work that's going to propel these communities forward". As a result of these dialogue and working group efforts, 
community engagement ideas were compiled by sustainability coordinators to assist NCC and others who may seek to engage and work with communities in NunatuKavut.

The community sustainability coordinators furthered community asset mapping (a new skill learned during workshops in HVGB) within their respective communities. This allowed them to capture broad and insightful responses while expanding community vision through the identification of community strengths and opportunities. Working from a place of strength was integral to this study and facilitated discussions around strength-based approaches to community planning were successful.

During the workshops (in group and as a whole) sustainability goals were identified and then further verified and expanded upon within each community through visioning exercises. During the workshops in HVGB, visioning exercises were employed where representative community members in attendance worked in community groups to map out an ideal vision for their respective communities. In doing so, community members articulated (through drawings) their hopes for the future. Early discussions about strength-based planning aided participants in creating visions that were positive, realistic and hopeful. Overall, these early visions were well thought out and discussed in detail. They created opportunities for in-depth participant discussion about what worked well in the community in the past and present, and participants identified the skills, knowledge and expertise the community already has and that they deem relevant to pursuing sustainable community development. Participants identified practical goals like infrastructure and water security projects, to name a few (See Table A3 for detailed community goals). These goals are fundamental to economic development opportunities. In addition, participants identified economic development opportunities like bakeapple harvesting and processing, the fishery, sealing, and tourism in resource and culture rich areas (see result five). The practicality of these goals was further supported by the participants 'ability to locate existing assets in the community that could assist with achieving the goals. For example, abandoned structures, buildings, empty homes, and materials and skills that already exist in the community were identified as spaces and opportunities to further the economic development ideas. Visions for sustainable economic development like berry and seal harvesting and tourism development in Black Tickle, the construction of a multi-purpose building in St. Lewis that could accommodate a cultural Centre and growing tourism opportunities, and tourism growth potential in Norman Bay, all point to sustainability planning that seeks to incorporate aspects of community and cultural life that are relevant and meaningful to Inuit themselves.

\subsection{Re-Connection to Community and Culture during the Planning Process}

Strength based exercises that encouraged positive thinking and reflection also aided in the re-connection to and validation of home and culture. Strength based dialogue facilitated opportunities for participants to re-connect to those aspects of home and community life that are most valuable to them. Borrowing from Corntassel's [24] work related to the interconnections between Indigenous peoples connection to land and resurgence, these re-connections described by participants are also interpreted as acts of resurgence by Inuit. For example, one community member wrote:

"I love St. Lewis because it's a place I call home. I can teach our children traditional ways of living like hunting, fishing and trapping. Things I learned growing up as a kid and stuff I can pass on to them ... don't think they would learn these things if we lived in a city".

There were ample stories (written and shared in discussions) that pointed to a high degree of pride in home across all three communities. It was obvious that by validating community and culture, people re-connected and became more engaged and responsive to thinking about the future from a place of strength and saw themselves as having a role in creating this vision for the future. Participants discussed some of the challenges and barriers that they continue to face in their communities, in a way that was solution oriented, as opposed to from a place of defeat and hopelessness, (a way of thinking apparent early on). For example, some community participants spoke about how policy and programming opportunities, or funding calls from provincial and federal governments, are often 
done without regard for the interests and goals of the communities. Some expressed how they felt invalidated over the years in their communities by provincial or federal governments and marginalized from funding and other crucial opportunities to pursue planning efforts that were important to them. Others felt that some government officials simply did not care about them or their communities and felt as though it was the tactic of government to have people relocate from their homes to lessen financial burden and responsibility of government. Yet by re-connecting to community and culture, participants were able to think outside of a pre-scripted box where programs and services are outlined by external actors, and were able to come up with ideas and goals that were directly related to the interests of the communities. We learned that community interests are integral to planning as many participants talked about, for example, the importance of ensuring the survival of tradition and life ways learned from their ancestors.

The strength-based exercises in this study were successful in validating the potential, expertise, and knowledge that exists in the study communities. This form of validation proved crucial to strengthening capacity and awareness for those involved in planning, and in overcoming feelings of defeat and isolation. Furthermore, the importance of community and cultural validation is a feature of sustainable self-determination that seek to counter colonial wrongdoings that deny people and communities their very Indigeneity. It appears that by re-connecting to community and culture in the planning process, participants become more engaged and take on a greater sense of responsibility for the future.

\subsection{Sustainability Goals Identified, and Implementation Begun}

The three pilot communities identified a range of community sustainability goals and priorities and they began to work towards design and implementation during the course of this study. (See Table A3 for more detail). The community goals and priorities identified illustrate that community members are aware of the need to provide for basic necessities in addition to priorities that impact holistic health and well-being. While these goals represent the voice and participation of Inuit, it is important to be alert to the ever-evolving realities that impact Inuit communities and the need for Inuit to evolve and adapt to these realities. This means that goals may change and evolve as well, and planning actors must be cognizant of this and capable of attending to the varying nature of planning in these communities. Participant work on the CGSI demonstrates a commitment to community and to ensuring the survival of communities. The sustainability work of the CGSI offered a dedicated space for community members to focus on key areas of interests as they relate to community survival. As a result, a community craft group was formalized, proposals for infrastructure development identified and furthered, proposals related to water security, as well as community craft and feast events, took place. Other long-term goals were identified and discussed including the diversification of industry for economic growth. Economic development ideas reflected the resources available to community, and the skills and knowledge of community members. For example, seal processing, berry processing and a range of tourism opportunities, were identified.

These goals and priorities came out of and were furthered through the asset mapping, visioning and engagement exercises. Further priorities and sustainability goals specifically included improvements to roads and transportation, water and sewer infrastructure (two of three communities lack water and sewer infrastructure entirely and the third, partially), infrastructure to support community development and growth (i.e., multipurpose community centre/fire hall), economic security, food and heat security initiatives, and culturally relevant education. Additionally, access to clean drinking water was identified as a goal across all three communities and the degree of urgency of this goal varied across communities, with the most urgent and priority need in Black Tickle. Each of these priority areas were considered important for community sustainability now and into the future.

Communities also identified initiatives that they felt could be undertaken immediately such as community gatherings and feasts to celebrate community (St. Lewis), art and craft sessions for communities and activities for youth (Norman Bay and Black Tickle). Community members identified 
these as opportunities to assist in sustaining the momentum around sustainability discussions that had been ongoing in their communities throughout the research. Community centred initiatives like these were also thought to positively impact collective well-being and promote togetherness, in turn reinforcing and further validating Inuit values. In this context, it is clear that community planning and development opportunities must adhere to principles that ensure the survival of community and culture in ways that respect and ensure the survival of the natural environment and all who live with it.

\subsection{Limitations}

The study faced some limitations and challenges such as geography. NunatuKavut spans a vast territory and the three pilot communities are not easily accessible to each other, nor for the research team. As a result, time in individual communities was limited due to costs associated with travel to remote coastal Labrador and in order to ensure that quality time was had in each community. Inadequate funding to support community sustainability coordinators beyond the life of this study due to the external funding opportunity being short term and project based was also a challenge for the longevity of continuing this work in communities.

\section{Discussion and Conclusions}

Topics of governance and sustainability, including community sustainability planning, are receiving increasing attention in Canada and across the globe. Yet, conflicts and tensions related to land and resources between Indigenous peoples and the state continue and often undermine Indigenous political autonomy [36]. When Indigenous political autonomy is undermined, so too are the sustainability of cultural landscapes and the social-ecological systems that Inuit are a part of. Booth and Muir [31] recognize that Indigenous planning is necessary in order for Indigenous peoples to effectively navigate their own terrain and to navigate federal and provincial forces on their land. Yet, these authors observe that little attention has been paid (in the literature, policy or practice) to this area. An Indigenous planning perspective is new and to some extent unrealized, though it remains necessary in overcoming some of the barriers and obstacles that face Indigenous peoples in planning for the future [31] and sustaining their communities and cultures.

This study illustrates decolonized and community led sustainability planning in action. Collaborative work with NunatuKavut Inuit has given rise to 'grounded decolonization' which refers to an approach that seeks to respect and honour the values, history and culture of those who belong to their homeland, in their place and time. It refers to decolonization that must take place in the context of people who live and are connected through generations. Simply put, it means that decolonizing efforts must be acutely aware, and cognizant of, the history and present of the people in their context-and on their own terms. From this vantage point, decolonization or decolonizing efforts must be designed, shaped and implemented in locally and context specific ways. Thus, grounding decolonization refers to the act of designing and implementing decolonizing efforts that have gained consensus and agreement from communities leading their own efforts. In the context of sustainability planning, decolonization can manifest as Indigenous consent and recognition of Indigenous priorities and expertise which are integral to the creation of sustainable communities.

Corntassel's concept of place further enlightens this study [24]. The community sustainability planning and capacity strengthening efforts of Inuit in NunatuKavut throughout the CGSI reflect the capacity and strength of Inuit to make decisions that impact them on their lands and informed by their own values and perspectives. The autonomy to make decisions that impact the future of Inuit communities in NunatuKavut, in a way that is indicative of Inuit values, world views and perspectives, is integral to decolonizing and self-determination efforts that are sustainable into the future. By building on the work of Corntassel in this area and applying key concepts and ideas to the work in NunatuKavut, we were able to assist communities in identifying short and long-term sustainability goals that positively impact community. Expertise and knowledge of generations past, 
of tradition, moving and living with changing seasons, all point to a reality in which people live in relation with the natural environment, not against it [4].

Study participants were active in achieving a number of the goals and objectives set out in their communities through the CGSI and it was clear that the health of people and communities, of lands and waters, was and is a stated priority. The priorities and goals set out by the communities in this study are meaningful, relevant and urgent. While they are not necessarily elaborate, it is important to understand these goals in context. In many ways, they reflect a desire for the basic and fundamental rights and privileges that most Canadians' already enjoy freely, including basic necessities necessary to support the planning and development of goals driven by the global economy (e.g., access to clean drinking water). Sustainability goals and priorities in this study point to inequalities and inequities that plague NunatuKavut Inuit in these areas, but these issues are not unique to them as Indigenous peoples. Water and food insecurity disproportionately impact Indigenous communities in Canada, and in particular, Northern Indigenous communities [37]. Thus, Indigenous led self-determination efforts that are locally driven and context specific are necessary for the planning of sustainable futures that promote equality and equity for Inuit.

Community asset mapping, engagement strategies, visioning exercises, and capacity strengthening initiatives provided spaces and environments for participants and communities to envision, for themselves, a future for their community. The idea behind capacity strengthening and thought-provoking exercises such as these was not to transport knowledge from one authoritative body onto community, but rather to open safe and meaningful spaces for communities to connect with, think about, and reflect upon what is possible in a way that positions community members as experts and knowledge holders in their own right. Following from the work of Eisenberg et al. [29], this research and the processes described in this study demonstrate that Indigenous peoples and communities are experts on their lands and their knowledge of place position them to make decisions to inform a future that is compatible with their own goals, ways of knowing and of being.

Overall, the work of the sustainability committees in communities set the stage for discussions whereby community people began to talk about governance and community planning from a community centered and value-based perspective. Several participants spoke to the way in which the sustainability committee in their community had allowed them to think about and move initiatives forward in a way that had not been possible before. Participants from all of the pilot communities spoke to the necessity of community involvement and leadership in decisions that impact them directly, emphasizing the importance of grounded, decolonizing approaches to community planning and visions for the future informed by Inuit goals and values, and shaped by their connection to people, place and history, rooted in their environment and culture.

Community knowledge, values and traditions, enlightened by communities themselves, has set an important expectation in motion-that in order to plan for a sustainable future, we must think about and reconnect with what it is that we value most about our communities. This approach allows community members to reflect and to think about positive aspects of a community (i.e., culture, values etc.), and to ensure that those facets of community are protected and considered in planning for the future. What is valued within and about community became the prominent factor in considering and determining community sustainability goals in these three pilot communities. This work situates grounded decolonization as that which creates, supports and fosters environments that allow communities and people to connect and re-connect to their communities in ways that are most meaningful to them. Decolonizing paths that seek to respond to the interests, priorities and values of people in their place and time, and not those ideals or values that come from outside the community, are particularly relevant. Grounded decolonization implies that these values about community should lead the community planning approach for the future.

Decolonized planning efforts are a necessary step to sustainable self-determination in NunatuKavut so as to ensure that community sustainability planning efforts come from a rights-based perspective. As a concept and point of discussion in modern day discourse and building on the work of Smith [20], 
decolonization can assist us in unpacking sites of colonial control (and even colonial relationships that have endured and continue to marginalize Indigenous governance systems). While Indigenous governance systems have much to contribute to the development of sustainable communities and societies, Indigenous communities are often faced with barriers due to a lack of interest in collaboration from dominant systems of control within society [22]. The implications of this work are that community sustainability for Indigenous communities under Indigenous led decolonization, as it is for the NunatuKavut Inuit, means that capacity is being strengthened, knowledge and awareness of Indigenous rights are becoming more prevalent, the desire and will to reclaim traditional aspects of culture and political society are more paramount, and the willingness to own, author and share one's story is becoming commonplace. This research study has been a witness to the power of culture, tradition and connection to community that has come as a result of decolonizing work, all of which are integral to beginning and maintaining decolonized community sustainability.

Author Contributions: A.H.: Supported by the NCC, I designed and led the CGSI, with the NCC and three NunatuKavut communities. I held a dual role as NCC employee, working with and for the communities, observing and reflecting on this process as a PhD student. The multiple roles of community member, researcher and employee of NCC held me accountable but also connected me with the communities and people who participated in this research. K.V.: My contributions to this paper are as a scholar in community sustainability, governance and development. As supervisor I provided guidance throughout the research, including the writing of this article and the related $\mathrm{PhD}$ dissertation, as well as specific input on the construction and content of this paper, as outlined below. Conceptualization, A.H.; methodology, A.H.; investigation, A.H.; resources, K.V.; writing-original draft preparation, A.H.; writing —review and editing, A.H., and K.V.; supervision, K.V. All authors have read and agreed to the published version of the manuscript.

Funding: The authors are grateful to the support of this work and the CGSI from NCC and participating communities, who provided essential input and in-kind support, and to the Atlantic Indigenous Mentorship Network: Kausattumi Grants Program scholarship.

Acknowledgments: The authors thank the communities of Black Tickle, Norman Bay and St. Lewis for their time, contributions, expertise and knowledge throughout this research. Special thanks to the NunatuKavut Community Council (NCC) for seeing the value in this research and for your support of this initiative throughout. The authors would also like to thank all of those who supported this research as partners, colleagues and friends, whose advice and guidance were invaluable to this research.

Conflicts of Interest: The authors declare no conflict of interest.

\section{Abbreviations}

NCC NunatuKavut Community Council

CGSI Community Governance and Sustainability Initiative

LIA Labrador Inuit Association

ACOA Atlantic Canada Opportunities Agency

RIRSD Recognition of Rights and Self-Determination

HVGB Happy Valley-Goose bay

\section{Appendix A. Community Characteristics}

Black Tickle, Norman Bay, and St. Lewis were selected as pilot communities to pursue community sustainability planning with a vision towards identifying collective community goals, building on what is and has already been working well in the communities, in order to envision a future from a place of strength, Inuit values and perspectives. This process demonstrated that residents in the three communities are proud and eager to reclaim and strengthen a future that is bright and sustainable for their families for the years to come. The communities were selected based on remote geography in NunatuKavut, their vulnerability around economic development, food and water security concerns (although to varying degrees in each community), and rate of population decline, all of which affect community and cultural preservation. These communities are also rich in Inuit culture and their remoteness and lack of basic amenities give rise to continued subsistence living in a way that persistently demonstrates Inuit adaptation in the face of globalization. In sum, this research is driven by an approach to equity. Table A1 provides an overview of the remoteness of all three communities, highlighting the lack accessibility in and out of each community and a lack of primary industry that was once the economic driver in the communities. 
Table A1. Community Characteristics.

\begin{tabular}{cccc}
\hline & Black Tickle & Norman Bay & St. Lewis \\
\hline Population $^{1}$ & 110 & 20 & 185 \\
\hline Transportation & $\begin{array}{c}\text { Fly-in/out, seasonal ferry } \\
\text { (limited), small boat }\end{array}$ & $\begin{array}{c}\text { Seasonal fly-in/out (helicopter), } \\
\text { small boat }\end{array}$ & $\begin{array}{c}\text { Road (TransLabrador } \\
\text { Highway, TLH), fly-in/out }\end{array}$ \\
\hline Major Industry & Fishery (local plant closed) & $\begin{array}{c}\text { Fishery (travel to neighboring } \\
\text { plant by boat for employment, } \\
\text { no local plant) }\end{array}$ & Fishery (local plant closed) \\
\hline 1 Population source: Community Town Council, Recreation Committee and Local Service District respectively. \\
Other information in Table 1 reflects knowledge from study participants.
\end{tabular}

Table A2. Data Collection Activities (All Communities).

\begin{tabular}{|c|c|c|c|}
\hline Activity Type & Participants (n) & Rationale & Impact \\
\hline Focus group & $\begin{array}{l}\text { Black Tickle: } 7 \\
\text { Norman Bay: } 2 \\
\text { St. Lewis: } 6\end{array}$ & $\begin{array}{l}\text { Participant knowledge } \\
\text { sharing and storytelling }\end{array}$ & $\begin{array}{l}\text { Participant voices privileged. } \\
\text { Increased understanding around } \\
\text { community vision, goals and } \\
\text { limitations. }\end{array}$ \\
\hline Interviews & $\begin{array}{l}\text { Black Tickle: } 1 \\
\text { Norman Bay: } 1 \\
\text { St. Lewis: } 2 \\
\text { Other: } 2\end{array}$ & $\begin{array}{l}\text { Standard data collection } \\
\text { method }\end{array}$ & $\begin{array}{l}\text { Less effective in accessing rich data. } \\
\text { Not conducive to storytelling. }\end{array}$ \\
\hline Survey & $\begin{array}{l}\text { Black Tickle: } \mathrm{n} / \mathrm{a} \\
\text { Norman Bay: } 6 \\
\text { St. Lewis: } 20\end{array}$ & Baseline data collection & $\begin{array}{l}\text { No surveys conducted in Black } \\
\text { Tickle given the nature of researcher } \\
\text { and community relationship (see } \\
\text { methods). For others, increased } \\
\text { researcher understanding of } \\
\text { participant belonging to community } \\
\text { (age, years in community, etc). }\end{array}$ \\
\hline $\begin{array}{l}\text { Community } \\
\text { gathering }\end{array}$ & $\begin{array}{l}\text { Black Tickle: } 25 \\
\text { Norman Bay: } 6 \\
\text { St. Lewis: } 43\end{array}$ & $\begin{array}{l}\text { Appropriate Indigenous } \\
\text { research method }\end{array}$ & $\begin{array}{l}\text { Designed to enable researcher } \\
\text { learning from participants. }\end{array}$ \\
\hline $\begin{array}{l}\text { Written } \\
\text { submissions }\end{array}$ & $\begin{array}{l}\text { Black Tickle: } 12 \\
\text { Norman Bay: } 12 \\
\text { St. Lewis: } 26\end{array}$ & $\begin{array}{l}\text { Create space for positive } \\
\text { and strength-based } \\
\text { thinking around } \\
\text { community }\end{array}$ & $\begin{array}{l}\text { Re-connected community to } \\
\text { positive attributes of community } \\
\text { and culture. Increased } \\
\text { understanding of participant values } \\
\text { in relation to community } \\
\text { and culture. }\end{array}$ \\
\hline $\begin{array}{l}\text { HVGB workshop } 1 \\
\text { (strength-based } \\
\text { planning, visioning, } \\
\text { asset mapping, } \\
\text { community } \\
\text { engagement, } \\
\text { proposal writing }\end{array}$ & $\begin{array}{l}\text { Black Tickle, } \\
\text { Norman Bay and } \\
\text { St.Lewis: } 10\end{array}$ & $\begin{array}{l}\text { Engage participants in } \\
\text { positive and } \\
\text { strength-based planning } \\
\text { and visioning, identify } \\
\text { range of community assets } \\
\text { and engagement strategies, } \\
\text { and highlight tips and best } \\
\text { practices in proposal } \\
\text { writing }\end{array}$ & $\begin{array}{l}\text { Participants increasingly saw } \\
\text { themselves as active agents and } \\
\text { better identified positive attributes } \\
\text { of communities integral to } \\
\text { successful planning, identified } \\
\text { planning opportunities and goals } \\
\text { that were realistic and integral to } \\
\text { core values around community life } \\
\text { and culture, and identified and } \\
\text { reflected on the many assets that } \\
\text { already exist in communities. } \\
\text { Strengthened community capacity } \\
\text { and researcher learned best practices } \\
\text { in engagement from communities. }\end{array}$ \\
\hline $\begin{array}{l}\text { HVGB workshop } 2 \\
\text { (pilot community } \\
\text { and NCC } \\
\text { presentations, } \\
\text { Q\&A, networking } \\
\text { and focus group) }\end{array}$ & $\begin{array}{l}\text { Black Tickle, } \\
\text { Norman Bay and } \\
\text { St.Lewis: } 10 \\
\text { Other: Approx } 5\end{array}$ & $\begin{array}{l}\text { Privilege community } \\
\text { participants as leaders, } \\
\text { experts and knowledge } \\
\text { holders expressing vison } \\
\text { for their community, } \\
\text { strengthen participant } \\
\text { capacity and presentation } \\
\text { skills, identify } \\
\text { opportunities to advance } \\
\text { goals, connect community } \\
\text { participants with } \\
\text { stakeholders, knowledge } \\
\text { sharing and storytelling }\end{array}$ & $\begin{array}{l}\text { Conversations revolved around } \\
\text { stated community interests and } \\
\text { needs, participants supported in } \\
\text { efforts to pursue planning activities, } \\
\text { centred feedback and opportunities } \\
\text { around community planning } \\
\text { interests and goals, provided } \\
\text { opportunities to connect with } \\
\text { potential funders, researchers, etc., } \\
\text { increased researcher understanding } \\
\text { around community planning goals } \\
\text { and associated community values. }\end{array}$ \\
\hline
\end{tabular}


Table A3. A3.1 Black Tickle Community Goals and Progress; A3.2 Norman Bay Community Goals and Progress; A3.3 St. Lewis Community Goals and Progress.

\begin{tabular}{l}
\hline A3.1 Black Tickle Community Go \\
\hline Goal \\
\hline Short-term: \\
Local garden integrated with \\
healthy eating program for \\
children. \\
Medium to long term: \\
Enhanced food security and child \\
development
\end{tabular}
events

Medium to long-term:

Intergenerational community engagement, holistic health, pride in culture and tradition.

Short-term: Education programs related to traditional knowledge and life skills

Medium to long term: youth and elder engagement, preservation of culture

Short-term: Further investigate
alternatives for water and sewer
Infrastructure
Medium to long term: Ensure
reliable access to clean drinking
water to community residents

\begin{tabular}{l}
\hline A3.2 Norman Bay Community Goa \\
\hline Goal \\
\hline Short-term: Identify opportunities \\
to upgrade and build needed \\
infrastructure \\
Medium to long-term: \\
Infrastructure opportunities and \\
upgrades to community centre, \\
helicopter pad, winter snowmobile \\
trail, garbage disposal site,
\end{tabular}

Short-term:

Community garden and

Greenhouse development

Medium to long-term:

Communal access to local source of fresh foods

\section{Short-term:}

Potable Water Drinking Unit

(PWDU)

Medium to long-term:

Reliable source of clean drinking water

\section{Short-term:}

Equipment for Fire Fighting

Medium to long-term:

Increased capacity to respond to community crisis.

and Progress

\section{Rationale and Benefits}

- Will provide fresh source of local food.

- Address local grocery store issues regarding fresh produce by providing local source of vegetables for purchase and sale.

- Benefits for youth education and health

\section{Progress}

- School aged children/youth have begun participation in small scale gardening at school.

- Community members continue to express interest in this goal.

- Events like winter carnivals and come home year celebrations provide opportunities to connect families to community and culture with lasting positive impacts for morale and health of community members.

- Develops community planning skills.

- Local craft group formalized with the assistance of the CGSI, applying for funds to host social events regularly (e.g., Christmas and Easter events).

- Educate children and youth in areas of traditional knowledge and life skills (e.g., traditional food preparation).

- Ensure valued skills and knowledge are passed on will be important to community survival.

- Benefits to overall health (mentally, physically, emotionally, etc.).

- Access to clean drinking water is a right.

- Local craft group has begun partnering with NCC to deliver programs though NCC's Inuit Education Program and Community Grants Funding.

- Local Service District (LSD), with help from the CGSI, has developed and submitted a proposal and accessed funding to do feasibility work around water security options.

als and Progress

\section{Rationale and Benefits}

- Expand contact list and connections for partnerships.

- Enhance community centre to meet community needs;

- Enhance transportation means, enhance safety for travel and transportation of goods.

\section{Progress}

Volunteer labour has sustained the centre to date. Community looks forward to additional developments.

- Discussions around funding opportunities have taken place.

- Promote community connectedness, self-sufficiency and access to nutritious food.

- Access to healthy food in light of need to travel for store bought goods.

Small community garden infrastructure purchased through successful funding proposal.

Increase self-sufficiency.

- Access to clean drinking water is a right.

- Increase access to clean water and particularly for aging population who otherwise rely on retrieving water with buckets from a brook.

No known progress to date.

- Health and safety concern.

- Increased self-sufficiency and response efforts during crisis.
No known progress to date. 
Table A3. Cont.

\begin{tabular}{|c|c|c|}
\hline \multicolumn{3}{|c|}{ A3.3 St. Lewis Community Goals and Progress } \\
\hline Goal & Rationale and Benefits & Progress \\
\hline $\begin{array}{l}\text { Short-term: } \\
\text { Crafting Workshops and social } \\
\text { events } \\
\text { Medium to long-term: } \\
\text { Increase community participation } \\
\text { in culturally relevant activities }\end{array}$ & $\begin{array}{l}\text { - Enhance community activity and } \\
\text { skills building } \\
\text { - Increase community cohesion and } \\
\text { improve social and mental } \\
\text { wellness across generations }\end{array}$ & Ongoing. \\
\hline $\begin{array}{l}\text { Short-term: } \\
\text { Host community Feasts } \\
\text { Medium to long-term: } \\
\text { Provide opportunities to come } \\
\text { together and share traditional } \\
\text { foods }\end{array}$ & $\begin{array}{l}\text { - Respond to community interests } \\
\text { in like events. } \\
\text { - Bring community together and } \\
\text { support most vulnerable. }\end{array}$ & Ongoing. \\
\hline $\begin{array}{l}\text { Short-term } \\
\text { Work towards necessary } \\
\text { Infrastructure Upgrades } \\
\text { Medium to long-term: } \\
\text { Upgrades to museum and new } \\
\text { build (fire hall) }\end{array}$ & $\begin{array}{l}\text { Enhance basic and necessary } \\
\text { infrastructure for community } \\
\text { planning and development } \\
\text { - To address health and safety } \\
\text { concerns of community members. }\end{array}$ & $\begin{array}{l}\text { Ongoing discussions and } \\
\text { identification of opportunities. }\end{array}$ \\
\hline $\begin{array}{l}\text { Short-term: } \\
\text { Identify solutions to address gaps } \\
\text { in water security } \\
\text { Medium to long-term: } \\
\text { Water and Sewer Infrastructure } \\
\text { expanded }\end{array}$ & $\begin{array}{l}\text { To address outstanding water } \\
\text { insecurity in some parts of the } \\
\text { community. } \\
\text { - Provide access to clean drinking } \\
\text { water to all community members. }\end{array}$ & Discussions ongoing. \\
\hline
\end{tabular}

\section{References}

1. Nilsson, A.E.; Larsen, J.N. Making Regional Sense of Global Sustainable Development Indicators for the Arctic. Sustainability 2020, 12, 1027. [CrossRef]

2. Whyte, K.P.; Brewer, J.P.; Johnson, J.T. Weaving indigenous science, protocols and sustainability science. Sustain. Sci. 2016, 11, 25-32. [CrossRef]

3. Johnson, J.T.; Howitt, R.; Cajete, G.; Berkes, F.; Louis, R.P.; Kliskey, A. Weaving Indigenous and sustainability sciences to diversify our methods. Sustain. Sci. 2016, 11, 1-11. [CrossRef]

4. Hibbard, M.; Lane, M.B.; Rasmussen, K. The Split Personality of Planning: Indigenous Peoples and Planning for Land and Resource Management. J. Plan. Lit. 2008, 23, 136-151. [CrossRef]

5. Ugarte, M. Ethics, Discourse, or Rights? A Discussion about a Decolonizing Project in Planning. J. Plan. Lit. 2014, 29, 403-414. [CrossRef]

6. McGregor, D. Representing and Mapping Traditional Knowledge in Ontario's Forest Management Planning. In Reclaiming Indigenous Planning; Walker, D., Natcher, D., Jojola, T., Eds.; McGill-Queen's University Press: Montréal, QC, Canada, 2013; pp. 414-435.

7. Porter, L. Indigenous Planning: From Principles to Practice. Plan. Theory Pract. 2017, 18, 639-640. [CrossRef]

8. Matunga, H. A Revolutionary Pedagogy of/for Indigenous Planning. Plan. Theory Pract. 2017, 18, 640-644. [CrossRef]

9. Mercer, N.; Parker, P.; Hudson, A.; Martin, D. Off-grid energy sustainability in Nunatukavut, Labrador: Centering Inuit voices on heat insecurity in diesel-powered communities. Energy Res. Soc. Sci. 2020, 62, 101382. [CrossRef]

10. Procter, A.; Chaulk, K. Our Beautiful Land: The Challenge of Nunatsiavut Land Use Planning. In Reclaiming Indigenous Planning; Walker, D., Natcher, D., Jojola, T., Eds.; McGill-Queen's University Press: Montréal, QC, Canada, 2013; pp. 436-456.

11. Gibson, R. Sustainability assessment and conflict resolution: Reaching agreement to proceed with the Voisey's Bay nickel mine. J. Clean. Prod. 2005, 14, 334-348. [CrossRef]

12. O'Faircheallaigh, C. Negotiations in the Indigenous World. Aboriginal Peoples and the Extractive Industry in Australia and Canada; Routledge: London, UK, 2016. 
13. Archibald, L.; Crnkovich, M. If Gender Mattered: A Case Study of Inuit Women, Land Claims and the Voisey's Bay Nickel Project; Status of Women Canada: Ottawa, ON, Canada, 1999. Available online: http://publications.gc. ca/collections/Collection/SW21-39-1999E.pdf (accessed on 13 May 2020).

14. Diggon, S.; Butler, C.; Heidt, A.; Bones, J.; Jones, R.; Outhet, C. The Marine Plan Partnership: Indigenous community-based marine spatial planning. Mar. Policy 2019, 5, 103501. [CrossRef]

15. Hudson, A. Re-claiming Inuit Governance: Revitalizing Autonomy and Sense of Place in Self-Determined Decision Making in NunatuKavut. Ph.D. Thesis, Memorial University of Newfoundland, St. John's, NL, Canada, 2020.

16. Baxter, K.H.; Purcell, M. Community Sustainability Planning. Munic. World 2007, 117, 35-38.

17. Vodden, K.; Lane, R.; Pollett, C. Seeking Sustainability through Self-Assessment and Regional Cooperation in Newfoundland and Labrador. In Sustainability Planning and Collaboration in Rural Canada; Hallstrom, L., Beckie, M., Hvenegaard, G., Mündel, K., Eds.; University of Alberta Press: Edmonton, AB, Canada, 2016; pp. 321-346.

18. Corntassel, J. Toward Sustainable Self-Determination: Rethinking the Contemporary Indigenous Rights Discourse. Alternatives 2008, 33, 105-132. [CrossRef]

19. Palmater, P. Indigenous Nationhood: Empowering Grassroots Citizens; Fernwood Publishing: Halifax, NS, Canada, 2015.

20. Smith, L.T. Decolonizing Methodologies: Research and Indigenous Peoples, 2nd ed.; Zed Books: New York, NY, USA, 2012.

21. Wilson, S. Research is Ceremony: Indigenous Research Methods; Fernwood Publishing: Halifax, NS, Canada, 2008.

22. Jokhu, P.D.; Kutay, C. Observations on Appropriate Technology Application in Indigenous Community Using System Dynamics Modelling. Sustainability 2020, 12, 2245. [CrossRef]

23. Patrick, R.; Grant, K.; Bharadwaj, L. Reclaiming Indigenous Planning as a Pathway to Local Water Security. Water 2019, 11, 936. [CrossRef]

24. Corntassel, J. Re-envisioning resurgence: Indigenous pathways to decolonization and sustainable self-determination. Decolon. Ind. Educ. Soc. 2012, 1, 86-101.

25. Kovach, M. Indigenous Methodologies: Characteristics, Conversations and Contexts; University of Toronto Press: Toronto, ON, Canada, 2009.

26. Fanon, F. The Wretched of the Earth; Grove Press Inc.: New York, NY, USA, 1963.

27. Borrows, J.; Rotman, L.I. Aboriginal Legal Issues: Cases, Materials, E Commentary; Butterworths: Toronto, ON, Canada, 1998.

28. Napoleon, V.; Friedland, H. An Inside Job: Engaging with Indigenous Legal Traditions Through Stories. McGill Law J. Rev. Droit McGill 2016, 61, 725-754. [CrossRef]

29. Eisenberg, A.; Webber, J.; Coulthard, G.; Boisselle, A. Recognition Versus Self Determination: Dilemmas of Emancipatory Politics; UBC Press: Vancouver, BC, Canada, 2014.

30. Lambert, L. Research for Indigenous Survival: Indigenous Research Methodologies in the Behavioral Sciences; University of Nebraska Press: Lincoln, MI, USA, 2014.

31. Booth, A.; Muir, B.R. Environmental and Land Use Planning Approaches of Indigenous Groups in Canada: An Overview. J. Environ. Policy Plan. 2011, 13, 421-442. [CrossRef]

32. Walker, W.; Haasnoon, M.; Kwakkel, J.H. Adapt or Perish: A Review of Planning Approaches for Adaptation under Deep Uncertainty. Sustainability 2013, 5, 955-979. [CrossRef]

33. Hart, M.A. Indigenous Worldviews, Knowledge, and Research: The Development of an Indigenous Research Paradigm. J. Indig. Soc. Dev. 2010, 1, 1-16.

34. Cooper, E.J.; Driedger, S.M. Creative, strengths-based approaches to knowledge translation within indigenous health research. Public Health 2018, 163, 61-66. [CrossRef]

35. Fawcett, B.R.; Walker, R.; Greene, J. Indigenizing City Planning Processes in Saskatoon, Canada. Can. J. Urb. Res. 2015, 24, 158-175. 
36. Lane, M.B.; Hibbard, M. Doing it for themselves: Transformative Planning by Indigenous peoples. J. Plan. Educ. Res. 2005, 25, 172-184. [CrossRef]

37. Hanrahan, M.; Sarkar, A.; Hudson, A. Exploring Water Insecurity in a Northern Indigenous Community in Canada: The "Never-Ending Job" of the Southern Inuit of Black Tickle, Labrador. Arct. Anthropol. 2014, 51, 9-22. [CrossRef]

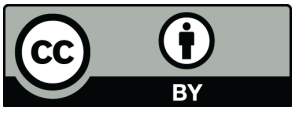

(C) 2020 by the authors. Licensee MDPI, Basel, Switzerland. This article is an open access article distributed under the terms and conditions of the Creative Commons Attribution (CC BY) license (http://creativecommons.org/licenses/by/4.0/). 